\title{
1-Butyl-3-Methyl Imidazolium Hydrogen Sulphate Promoted One-Pot Three-Component Synthesis of Amidoalkyl Naphthols
}

\author{
Suryakant B. Sapkal, Kiran F. Shelke, Balaji R. Madje, Bapurao B. Shingate, and Murtidhar S. Shingare* \\ Department of Chemistry, Dr. Babasaheb Ambedtar Harathwada Lniversitv, Aurangabad-431 004, India \\ E-mail: msshingare orgiáredifmail.com \\ Received July 10, 2009, Accepted Alugust 22, 2009
}

\begin{abstract}
An efficient and easy method for one-pot three-component synthesis of amidoalkyl naphthols by the condensation of aromatic/neteroaromatic/aliphatic aldehydes, 2-naphthol and amides or urea under themmal condition at $60{ }^{\circ} \mathrm{C}$ in the presence of acidic ionic liquid l -butyl-3-methy linidazolium hy drogen sulphate ([bmim] $\mathrm{HSO}_{4}$ ) has been described.
\end{abstract}

Key Words: Amidoalkyl naphthols. Ionic liquid. Operational simplicity. Three-component

\section{Introduction}

Compounds bearing 1,3-amido oxygenated functional groups are ubiquitous to a variety of biologically important natural products and potent drugs including a number of nucleoside antibiotics and HIV protease inhibitors such as ritonavir. lipinavir and the hy potensive and bradycardiac effects of these compounds have been evaluated. ${ }^{1.2}$ It is noteworthy that l-amidoalkyl-2naphthols can convert into important biological active l-aminoalkyl-2-naphthol derivatives by hydrolysis reaction. ${ }^{2,3}$ The importance of amidoalkỵl naphthols for their synthesis has attracted renewed attention and various improved procedures have been reported. Many of these reported methods employs catalysts. such as $p$-TSA. iodine ${ }^{5}$ sulphamic acid ${ }^{6}$ montmorillonite $\mathrm{K}-10$ clay. $\mathrm{Ce}\left(\mathrm{SO}_{4}\right){ }_{2}{ }^{8}$ cation-exchanged resin, ${ }^{9}$ zirconyl (IV)

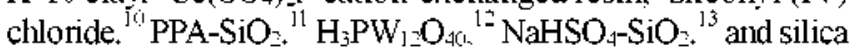
sulfuric acid. ${ }^{\text {lt }}$ These methods have various drawbacks such as prolonged reaction time. low yields. toxicity. low recovery and reusability of the catalyst (Table 1). Therefore introduction of clean procedures and utilizing ecofriendly green catalyst can be simply recycled at the end of reaction have attracted more attention.

Multicomponent condensations constitutes an especially attractive sy nthetic strategy for rapid and efficient library generation due to the fact that the products are formed in a single step and the diversity can be achieved simply by varying the reacting components. ${ }^{15}$ Very recently, we have reported the convenient șynthesis of polỵydroquinolines and 2.4.5-triarỵlimidazole derivatives via nulticomponent condensation reaction. ${ }^{16,1}$ ?

Due to the emvironmental concerns, the use of benign solvents as an altemative to volatile organic solvents and are of much interest to organic chemist. The use of ionic liquid as a reaction media and catalyst can offer a solution to solvent emission and cataly'st recycle problems. ${ }^{18.19}$ Ionic liquid posses the advantages like negligible vapour pressure, thermal stability, recyclability and dissolve many orgauic substrates. ${ }^{20}$ In view of the emerging importance of imidazolium based ionic liquids as a novel reaction media herein, we wish to explore the use of ionic liquids as promoters and recyclable solvent sy stems for an one-pot threeconponent synthesis of amidoalkyl naphthol derivatives under nuild conditions (Scheme 1).

In continuation of our interest in finding new environmentally benign methods for the synthesis of various compounds ${ }^{21.24}$ and use of various ionic liquids for organic transformations. "Herein we want to report for first time. the rapid and selective synthesis of amidoalkyl naphthols in the presence of [bmim] $\mathrm{HSO}_{4}$ ionic liquid as a Bronsted acidic ionic liquid.

Singh and coworkers reported the synthesis of [bmint] $\mathrm{HSO}_{4}$ ionic liquid and its application for the synthesis of coumarins. ${ }^{2}$ Ionic liquid teclunology. when used in place of chemical organic

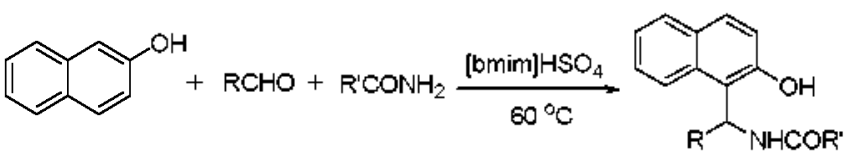

Scheme 1

Table 1. Comparison results for the condensation of benzaldehyde, 2-naphthol and acetamide in the presence of ionic liquid with literature.

\begin{tabular}{|c|c|c|c|c|c|c|}
\hline Entry & Catalyst & Amount of catalyst & Time (min) & Yield (\%) & Condition & Reference \\
\hline 1 & $p$-TSA & $\begin{array}{l}0.1 \mathrm{mmol} \\
0.1 \mathrm{mmol}\end{array}$ & $\begin{array}{l}720 \\
300\end{array}$ & $\begin{array}{l}90 \\
88\end{array}$ & $\begin{array}{c}\mathrm{RT} \\
125^{\circ} \mathrm{C}\end{array}$ & 4 \\
\hline 2 & $I_{\hat{\vartheta}}$ & $5 \mathrm{~mol} \%$ & 720 & 91 & RT & 5 \\
\hline 3 & - & - & 270 & 87 & $125^{\circ} \mathrm{C}$ & 5 \\
\hline 4 & $\mathrm{Z}_{1} \mathrm{OCl}_{2}$ & $0.1 \mathrm{mmol}$ & 840 & 86 & RT & 10 \\
\hline 5 & $\mathrm{H}_{3} \mathrm{PW}_{\mid \leqslant} \mathrm{O}_{41\rangle}$ & $2 \mathrm{~mol} \%$ & 80 & 90 & $100^{\circ} \mathrm{C}$ & 12 \\
\hline 6 & Silica sulfurtic acid & $20 \mathrm{mg}$ & 120 & 85 & RT & 14 \\
\hline 7 & [bmim] $\mathrm{HSO}_{4}$ & $5 \mathrm{~mol} \%$ & 30 & 96 & $60^{\circ} \mathrm{C}$ & Present work \\
\hline
\end{tabular}


Table 2. Effect of different ionic liquids in the reaction of benzaldehyde, 2-naphthol and acetamide.

\begin{tabular}{|c|c|c|c|}
\hline Entry & Ionic liquid & Time $(h)$ & Yield $(\%)^{\sigma}$ \\
\hline 1 & [bmim] $\mathrm{BF}_{+}$ & 2 & 45 \\
\hline 2 & [bminn] $\mathrm{PF}_{6}$ & 2 & 40 \\
\hline 3 & [buminin] $\mathrm{Cl}$ & 2 & 55 \\
\hline 4 & [bmim]Cl & 2 & 55 \\
\hline 5 & [bmim] $\mathrm{HSO}_{4}$ & $30 \mathrm{~min}$ & 96 \\
\hline 6 & - & 5 & 30 \\
\hline
\end{tabular}

Isolated vield.

Table 3. Synthesis of amidoalkvl naphthols.

\begin{tabular}{|c|c|c|c|c|c|}
\hline Entry & $\mathrm{R}$ & $\mathrm{R}^{\prime}$ & $\begin{array}{l}\text { Time } \\
\text { (minin) }\end{array}$ & $\begin{array}{c}\text { Yield } \\
(\%)\end{array}$ & $\begin{array}{l}\text { M.P. } \\
\left({ }^{\circ} \mathrm{C}\right)^{\text {Ret }}\end{array}$ \\
\hline 1 & $\mathrm{C}_{6} \mathrm{H}_{5}$ & $\mathrm{CH}_{3}$ & 30 & $\begin{array}{c}96 \\
(96,94,95)^{\mathrm{b}}\end{array}$ & $228-230^{5}$ \\
\hline 2 & $3-\mathrm{NO}_{2} \mathrm{C}_{6} \mathrm{H}_{4}$ & $\mathrm{CH}_{3}$ & 55 & 92 & $237-239^{117}$ \\
\hline 3 & $4-\mathrm{ClC}_{5} \mathrm{H}_{4}$ & $\mathrm{CH}_{3}$ & 35 & 93 & $231-133^{10}$ \\
\hline 4 & $2-\mathrm{CH}_{3} \mathrm{C}_{n} \mathrm{H}_{4}$ & $\mathrm{CH}_{3}$ & 40 & 90 & $201-203^{5}$ \\
\hline 5 & $2-\mathrm{ClC}_{6} \mathrm{H}_{4}$ & $\mathrm{CH}_{3}$ & 40 & 89 & $197 \sim 199^{5}$ \\
\hline 6 & $4-\mathrm{FC}_{n} \mathrm{H}_{4}$ & $\mathrm{CH}_{3}$ & 35 & 92 & $204-206^{11}$ \\
\hline 7 & $3,4-\mathrm{OCH}_{3} \mathrm{C}_{5} \mathrm{H}_{3}$ & $\mathrm{CH}_{3}$ & 45 & 90 & $234-236^{17}$ \\
\hline 8 & $4-\left(\mathrm{CH}_{2}\right)_{2} \mathrm{NC}_{6} \mathrm{H}_{4}$ & $\mathrm{CH}_{3}$ & 45 & 94 & $125-127^{11}$ \\
\hline 9 & $\mathrm{C}_{2} \mathrm{H}_{5}$ & $\mathrm{CH}_{3}$ & 50 & 84 & $173 \cdots 175^{10}$ \\
\hline 10 & $\left(\mathrm{CH}_{3}\right)_{2} \mathrm{CH}$ & $\mathrm{CH}_{3}$ & 47 & 82 & $181 \cdots 183^{1-4}$ \\
\hline 11 & $\mathrm{C}_{3} \mathrm{H}_{9}$ & $\mathrm{CH}_{3}$ & 47 & 80 & $190 \sim 192^{14}$ \\
\hline 12 & 2-Furyl & $\mathrm{CH}_{3}$ & 45 & 90 & $218-220^{5}$ \\
\hline 13 & $\mathrm{C}_{6} \mathrm{H}_{5}$ & $\mathrm{C}_{5} \mathrm{H}_{5}$ & 45 & 90 & $235-237^{11)}$ \\
\hline 14 & $4-\mathrm{CH}_{2} \mathrm{C}_{6} \mathrm{H}_{+}$ & $\mathrm{C}_{6} \mathrm{H}_{5}$ & 45 & 88 & $190-192^{8}$ \\
\hline 15 & $4-\mathrm{FC}_{n} \mathrm{H}_{4}$ & $\mathrm{C}_{k} \mathrm{H}_{s}$ & 40 & 91 & $193 \cdots 195^{8}$ \\
\hline 16 & $\mathrm{C}_{n} \mathrm{H}_{3}$ & $\mathrm{NH}_{2}$ & 35 & 92 & $174 \cdots 176^{8}$ \\
\hline 17 & $4-\mathrm{ClC}_{6} \mathrm{H}_{4}$ & $\mathrm{NH}_{2}$ & 35 & 90 & $169--170^{5}$ \\
\hline 18 & 2-Thienyl & $\mathrm{NH}_{2}$ & 45 & 90 & $160-162^{13}$ \\
\hline 19 & 2-Pyridyl & $\mathrm{NH}_{2}$ & 45 & 88 & $153-155^{13}$ \\
\hline 20 & $\left(\mathrm{CH}_{3}\right)_{2} \mathrm{CHCH}_{2}$ & $\mathrm{NH}_{2}$ & 47 & 80 & $186-188^{-1}$ \\
\hline
\end{tabular}

"Yield refer to isolated pure products. All known products have been reported previously in the literature and were characterized by comparison of 'H NMR and MS spectra with authentic sample. "Yields after recovery of [bmim] $\mathrm{HSO}_{4}$

solvents. may' offer an environmentally benign approach toward modern synthetic chemistry. ${ }^{23}$

\section{Experimental}

I-Butyl-3-metlylimidazolium hydrogen sulphate ([bmim] $\mathrm{HSO}_{4}$ ) was prepared according to literature procedure. ${ }^{26}$ All the melting points were taken in an open capillary and are uncorrected. The progress of the reactions was monitored by thin layer chromatography (TLC). IR spectra were recorded on PerkinElmer FT-IR spectrophotometer in $\mathrm{KBr}$ disc. ${ }^{\mathrm{H}} \mathrm{H}$ NMR spectra were recorded on mercury plus Varian spectrometer at $400 \mathrm{MHz}$ in $\mathrm{CDCl}_{3}$ as a solvent and chemical shift values are recorded in units $\delta(\mathrm{ppm})$ relative to tetrametlyylsilane $\left(\mathrm{Me}_{4} \mathrm{Si}\right)$ as an internal standard.

Experimental procedure for the synthesis of amidoalkyl na- phthols. A nuixture of aldelydes (1 numol), 2-1naphthol (1 nunol) and amide or urea $(1.1 \mathrm{mmol})$ in [bmim] $\mathrm{HSO}_{4}(5 \mathrm{~mol} \%)$ at 60 ${ }^{\circ} \mathrm{C}$ was stirred for the time as shown in Table 3 . The progress of reaction was monitored by TLC. On completion, the reaction mixture was cooled at room temperature. Then it was extracted with ethyl acetate $(2 \times 20 \mathrm{~mL})$ leaving behind $[\mathrm{bmim}] \mathrm{HSO}_{4}$, organic layer washed by brine $(2 \times 10 \mathrm{~mL})$ solution and dried over sodium sulphate. The organic layer was evaporated under reduced pressure. The solid obtained was crystallized from ethanol to get pure product.

\section{Results and Discussion}

Our initial investigation focused on the use of ionic liquid as solvent as well as catalyst for the synthesis of amidoalkyl naphthols. In search of an efficient ionic liquid and the best experimental condition the reaction of benzaldehyde. 2-naphthol and acetamide (Table 3 . entry 1 ) at $60^{\circ} \mathrm{C}$ in the presence of ionic liquid has been considered as the model reaction (Scheme 1).

In order to optinizing the reaction condition it was found that the best results were obtained with $5 \mathrm{~mol} \%$ of $[\mathrm{bmim}] \mathrm{HSO}_{4}$ ionic liquid at $60^{\circ} \mathrm{C}$. The reaction was completed within $30 \mathrm{mi}-$ nutes and the expected product (Table 3, entry 1) was obtained in $96 \%$ yield (Scheme I). A variety of ionic liquids were employed for this synthesis. After successful screening of different ionic liquids such as I-butyl-3-methylimidazolum tetrafluroborate (bmim]BF ${ }_{4}$ ). l-butỵl-3-methylimidazolium hexaflurophosphate ([bnim] $\mathrm{PF}_{6}$ ), 1-butyl-3-dimethylimidazolium chloride ([bmim] Cl), l-benzyyl-3-methylimidazolium chloride ([bnmim] $\mathrm{Cl}$ ) and 1-buty 1-3-methylimidazolium hydrogen sulphate ([bmim] $\mathrm{HSO}_{4}$ ) for the model reaction and found that. [bmim] $\mathrm{HSO}_{4}$ was the best promoter for this reaction. These results are listed in Table 2.

The data collected in Table 2 indicates that. in the absence of ionic liquid the reaction occur at longer time with low yield of product. (Table 2. entry 6 ). To determine the appropriate condition of temperature, we have investigated the model reaction of 2-naphthol. benzaldelyde and acetamide in the presence of [bmim] $\mathrm{HSO}_{4}$ for 30 minute at different temperature of 50.60 and $70^{\circ} \mathrm{C}$. We found the formation of product in 75,96 and $96 \%$ yields respectively. This indicates that the temperature $60^{\circ} \mathrm{C}$ is sufficient for the best results of reaction by considering the yield of products. Encouraged by this protocol, we extended this reaction on substituted aromatic/heteroaromatic/aliphatic aldehydes. 2-naphthol and anides or urea under similar conditions. furnishing the respective amidoalkyl naphthols in excellent yields $(80-96 \%)$. But the same model reaction in the presence of [bmim] $\mathrm{HSO}_{4}$ cataly'st performed with I-naphthol afford the nixture of 2-substituted and 4-substituted anidoalkyl naphthol that required chromatographic separation techniques.

Also we have investigated the reusability of [bmim] $\mathrm{HSO}_{4}$ and observed that the ionic liquid was successfully reused for four cycles without significant loss of activity (Table 3. entry 1). The aromatic and heteroaromatic aldelydes undervent smoothly and gave in higher yields but aliphatic aldehy'de (Table 3. entries $9.10,11.20$ ) afforded conparatively low yield of product $(80 \sim 84 \%)$. Aromatic aldehydes containing both electron-withdrawing and electron-donating groups afforded the desired pro- 
ducts and are summarized in Table 3 . The formations of products were confirmed by physical and spectroscopic data and are in good agreement with reported one. The simple experimental and product isolation procedure combined with ease of recovery and reusability of ionic liquid is expected to the development of green strategy for the synthesis of amidoalkyl naphthols.

\section{Conclusion}

In conclusion. we have developed very simple and efficient methodology for the high y ielding synthesis of amidoalkyl niphthols by the straight forward one-pot three-component condensation of aromatic/heteroaromatic/aliphatic aldehydes. 2naphthol and amides or urea at mild $\left(60^{\circ} \mathrm{C}\right)$ condition in acidic ionic liquid. The operational simplicity of the procedure. shorter reaction time, simple workup procedure. cost effective recovery and reusability of ionic liquid make this method much attractive.

Ackow ledgments. We gratefully acknowledge the financial support received for this research work from the University Grants Commission (UGC), New Delhi.

\section{References}

1. Dingenmann, T.; Steinhilber, D.: Folkers, G. In Molecular Biology in Medicinal Chemistry. Wiley-VCH: Weinhein, 2003.

2. Shen, A. Y.; Tsai, C. T.; Chen, C. L. Emr. J. Med. Chent 1999, 34, 877

3. Shen, A. Y: Chen, C. L.: Lin, C. I. Chin. J. Physiol 1992, $35,45$.

4. Khodaei, M. M:; Khostopour, A. R.; Moghanian, H. Snlett 2006, 916

5. Das, B.; Lavminaravana, K: Ravikanth, B.; Rao, B. R. J. Mol.
Catal. A: Chem. 2007, 261, 180 .

6. Patil, S. B.; Singh, P. R.: Surpur, M. P.: Samant, S. D. Litrason. Sonochem. 2007, 14,515.

7. Kantevari, S: Vuppalapati, S. V. N.; Nagarapu, L. Catal. Commun. $2007,8,1857$.

8. Selvam, N. P.: Perumal, P. T. Tetrahedron Lett. 2006, $47,7481$.

9. Patil, S. B.; Singh, P. R.: Surpur, M. P.; Samant, S. D. Synth. Contmin. 2007, 37, 1659.

10. Nagawade, R. R.; Shinde, D. B. Acta Chm. Solv $2007,54,642$.

11. Shaterian, H. R.: Hosseinian, A.; Ghashang, M. Symh. Commm. $2008,38,3375$.

12. Dorehgiraee, A:; Khabazzadeh, H.; Saidi, K. Awkoc 2009, vii, 303.

13. Shaterian, H. R.: Hosseinian, A.: Ghashang, M. Tetrahedron Lett. $2008,+9.5804$.

14. Srihari, G.: Nagarạin, M; Murthy, M. M. Hetee. Chem Acta 2007 . $90,1497$.

15. Tejedor, D.; Garcia-Tellado, F. Chent. Soc. Rev 2007, 36, 484.

16. Sapkal, S. B.: Shelke, K. F.: Shingate, B. B.: Shingare, M. S. Tetrahedron Lett. 2009, 50, 1754.

17. Shelke, K. F.; Sapkal, S. B.; Shingare, M. S. Chin. Chen Lent. 2009, 20, 283.

18. Welton. T. Chem. Rev. 1999.99.2071.

19. Sheldon, R. Chem. Commm. 2001, 2399.

20. Kwan, J.; Kim, M. T. J. Org. Chem. 2002, 67,6845.

21. Sadaphal, S. A.; Markhele, V. M.; Sonar, S. S.; Shingare, M. S. $J$. Kowan Chem. Soc. 2008, 52, 454.

22. Pawar, S. S.: Dekhane, D. V.: Shingare, M. S.; Thore, S. N. Tetrahedron Lett. 2008, $19,4252$.

23. Hangarge, R. V. Shingare, M. S. Gren Chem. 2002, 4, 266.

24. Hangarge, R. V: Karale, B. K: Mane, A. S.; Chavan, V. P: Jarikote, D. V.: Shingare, M. S. Geen Chem 2001. 3. 310 .

25. Rong, M.: Lill, C.; Han, J.: Wang, H. Catal Commum 2009, 10 . 362 .

26. Singh, V; Kaur, S.; Sapehiyia, V; Singh, T; Kad, G. L. Cotal. Commun 2005, 6,57 .

27. Jain, S. L.; Joseph, J. K.: Sain, B. Cat. Lett. 2007, 115, 52. 